\section{(6) OPEN ACCESS}

For numbered affiliations see end of article.

\section{Correspondence to Dr Patrick N Breysse} Department of Environmental Health Sciences, Johns Hopkins Bloomberg School of Public Health, 615N. Wolfe St, Baltimore, Maryland 21205, USA; pbreysse@jhsph.edu

Received 2 November 2011 Accepted 29 July 2012

Published Online First 4 September 2012

\title{
Environmental monitoring of secondhand smoke exposure
}

\author{
Benjamin J Apelberg, ${ }^{1}$ Lisa M Hepp, ${ }^{2}$ Erika Avila-Tang, ${ }^{1,3}$ Lara Gundel, ${ }^{4}$ \\ S Katharine Hammond, ${ }^{5}$ Melbourne F Hovell, ${ }^{6}$ Andrew Hyland, ${ }^{7}$ \\ Neil E Klepeis, ${ }^{8}$ Camille C Madsen, ${ }^{2}$ Ana Navas-Acien, ${ }^{9}$ James Repace, ${ }^{10}$ \\ Jonathan M Samet, ${ }^{11}$ Patrick N Breysse ${ }^{9}$
}

\section{ABSTRACT}

The complex composition of secondhand smoke (SHS) provides a range of constituents that can be measured in environmental samples (air, dust and on surfaces) and therefore used to assess non-smokers' exposure to tobacco smoke. Monitoring SHS exposure (SHSe) in indoor environments provides useful information on the extent and consequences of SHSe, implementing and evaluating tobacco control programmes and behavioural interventions, and estimating overall burden of disease caused by SHSe. The most widely used markers have been vapour-phase nicotine and respirable particulate matter (PM). Numerous other environmental analytes of SHS have been measured in the air including carbon monoxide, 3-ethenylpyridine, polycyclic aromatic hydrocarbons, tobacco-specific nitrosamines, nitrogen oxides, aldehydes and volatile organic compounds, as well as nicotine in dust and on surfaces. The measurement of nicotine in the air has the advantage of reflecting the presence of tobacco smoke. While PM measurements are not as specific, they can be taken continuously, allowing for assessment of exposure and its variation over time. In general, when nicotine and PM are measured in the same setting using a common sampling period, an increase in nicotine concentration of $1 \mu \mathrm{g} / \mathrm{m}^{3}$ corresponds to an average increase of $10 \mu \mathrm{g} / \mathrm{m}^{3}$ of PM. This topic assessment presents a comprehensive summary of SHSe monitoring approaches using environmental markers and discusses the strengths and weaknesses of these methods and approaches.

\section{INTRODUCTION}

In this series of articles, three topic assessments summarising current knowledge about measuring secondhand smoke exposure (SHSe) are presented, covering self-reported measures, environmental measurements and biomarkers, and are based on a multidisciplinary expert meeting held in late 2008 at Johns Hopkins University, Baltimore, USA and supported by the Flight Attendant Medical Research Institute (FAMRI). The meeting addressed SHS assessment approaches to provide uniform methods for FAMRI investigators and others, and to set the stage for innovation. The topic assessments reflect the course of discussion at the meeting, along with recommendations developed from meeting participants, who were established researchers in one of the three focus areas. This article describes methods and strategies used to measure SHSe in the environment, strengths and weaknesses, and approaches discussed and recommended at the expert meeting.

\section{CHARACTERISTICS OF SECONDHAND SMOKE}

SHS, a mixture of thousands of components many of which are toxic and carcinogenic ${ }^{1}$ is made up of the mainstream smoke exhaled by the smoker and side stream smoke expelled from the end of a lit tobacco product. SHS concentration in the indoor environment depends on the number of cigarettes smoked in a period of time, the volume of the room, the ventilation rate and other processes that eliminate pollutants from the air. These processes vary based on the physical state and properties of the SHS component being measured. In 1986, the National Research Council (NRC), USA, proposed that an environmental marker of SHSe should be 'unique or nearly unique to the tobacco smoke so that other sources are minor in comparison, a constituent of the tobacco present in sufficient quantity such that concentrations of it can be easily detected in air, even at low smoking rates, similar in emission rates for a variety of tobacco products, and in a fairly consistent ratio to the individual contaminant of interest or category of contaminants of interest (eg, suspended particulates) under a range of environmental conditions encountered and for a variety of tobacco products'.

Historically, SHSe has been assessed principally by measuring airborne particulate matter (PM) and gas phase nicotine. In the 1980's it was established that cigarette smoking is a potent source of fine indoor airborne $\mathrm{PM},{ }^{34}$ and that gas phase nicotine was a sensitive and specific marker of $\mathrm{SHSe}^{5-7}$ Some markers are specific to tobacco smoke, while others may arise from a variety of sources. None of the environmental markers in use, however, meet all of the 1986 NRC criteria and no single component will reflect the full disease risk from the complex mixture that comprises SHS. ${ }^{89}$ The choice of method for measuring environmental SHS concentrations will therefore depend on the study's purpose. $^{10}$

\section{Evaluating sources and microenvironments}

Microenvironments are defined as a fixed location in which a person is exposed to SHS or another pollutant. Typical microenvironments include home, work, hospitality venues (eg, restaurants), school, or automobile. Average SHSe of an individual is the sum of airborne concentrations within 
each microenvironment $\left(c_{i j}\right)$ multiplied by the time spent within each microenvironment $\left(t_{i j}\right)$, divided by the total time being considered. The following mass balance equation (adapted from the 2006 Surgeon General's Report $(\mathrm{SGR})^{8}$ ), is used:

$$
\mathrm{E}_{\mathrm{avg}}=\frac{\sum \mathrm{c}_{\mathrm{ij}}{ }^{*} \mathrm{t}_{\mathrm{ij}}}{\sum \mathrm{t}_{\mathrm{ij}}}
$$

where concentration is a function of source strength (number of cigarettes smoked in a given unit of time), room volume, air exchange rates and other removal mechanisms (eg, deposition and chemical reaction). ${ }^{11-13}$

Table 1 lists the major microenvironments and the key factors that govern how exposure occurs within them. Many studies have described the impact of building size, construction, types of tobacco products smoked, forced or natural air movement, and proximity of smokers and non-smokers on concentrations of SHS constituents in common microenvironments. ${ }^{14} 16181921$ In indoor environments, the most influential building characteristics are generally room size and ventilation rate. The effects of forced and natural ventilation, as well as air flow in homes, on pollutant concentrations have been measured and studied theoretically. ${ }^{16}{ }^{19}$ For outdoor settings, proximity to smokers and wind speed and direction are most influential. ${ }^{14}$ Outdoor exposure only occurs during active smoking or shortly afterwards, as even low wind speeds will rapidly disperse the smoke.

Validated models can be used to estimate SHS concentrations for typical microenvironments. ${ }^{3} 81223$ Models based on mass balance equations can predict peak concentrations or timeweighted averaged (TWA) concentrations of SHS markers, (an extensive overview of the application of modelling to predicting particulate matter from SHS is given in Repace, ${ }^{23} \mathrm{Ott}^{24}$ and Ott et $a l^{25}$ ).

Modelling applications include assessing effectiveness of control measures, ${ }^{8} 12162627$ interpreting results of field studies, ${ }^{12}$ and conducting SHS risk assessment. ${ }^{28}$ These models can be coupled with pharmacokinetic models to estimate or interpret biomarkers for SHS dose. ${ }^{8} 26$

\section{METHODS FOR SHS ENVIRONMENTAL MONITORING}

A wide range of approaches has been used to evaluate SHSe. Assessment methods can be grouped based on the chemical target and the collection method (table 2).

\section{Airborne sampling}

Many SHS components can be measured using either active or passive sampling. Active sampling uses a pump to draw air into

Table 1 Summary of microenvironments and the factors that govern how exposure occurs within them

\begin{tabular}{lll}
\hline Microenvironments & Physical factors & Behavioural factors \\
\hline $\begin{array}{l}\text { Outdoors } \\
\text { Residences (indoors) }\end{array}$ & $\begin{array}{l}\text { Wind speed, wind direction } \\
\text { Room volume, window } \\
\text { positions, door positions, } \\
\text { HVAC* }\end{array}$ & $\begin{array}{l}\text { Proximity to smokers } \\
\text { Room location of } \\
\text { smoker(s), proximity } \\
\text { to smoker(s) }\end{array}$ \\
$\begin{array}{l}\text { Work/office/public } \\
\text { building (indoors) }\end{array}$ & Room volume, HVAC & $\begin{array}{l}\text { Room location of } \\
\text { smokers, proximity } \\
\text { to smoker(s) }\end{array}$ \\
$\begin{array}{l}\text { Restaurant/tavern } \\
\text { Automobile cabin }\end{array}$ & $\begin{array}{l}\text { Room volume, HVAC } \\
\text { Cabin volume, window }\end{array}$ & $\begin{array}{l}\text { Proximity to smoker(s) } \\
\text { Arm position, }\end{array}$ \\
& $\begin{array}{l}\text { position, air conditioning, } \\
\text { sriving speed }\end{array}$ & \\
\hline
\end{tabular}

*HVAC, heating, ventilation and air conditioning. the sample collection device, usually a filter or adsorbent tube, depending on the constituent of interest. Passive monitoring relies on diffusion to a collection surface. Both approaches allow investigators to measure an integrated time-weighted average (TWA) concentration over the sampling period. Direct reading methods, available for some SHS components, allow for realtime measurement of concentration over a variety of time intervals.

\section{Nicotine}

Airborne nicotine has been a widely used indicator for SHS in occupational and non-occupational environments. ${ }^{8} 35$ 74-76 The measurement of airborne nicotine a tobacco-specific constituent reflects tobacco smoke exposure. Sample collection methods are straightforward, and analytical methods are sensitive at low concentrations. ${ }^{35} 7778$ Methods to measure real-time concentrations of air nicotine are not available.

Nicotine sampling is typically conducted using a passive sampler. The sampling device, first described by Hammond and Leaderer, ${ }^{5}$ is a $35 \mathrm{~mm}$ polystyrene sampling cassette holding a filter treated with sodium bisulfate and covered by a diffusion screen allowing air to pass at a constant flow rate. Because the effective sampling rate is relatively low $(25 \mathrm{ml} / \mathrm{min})$, passive monitors are typically deployed from days to weeks, depending on the expected nicotine concentration. Exposed filters are extracted and nicotine is typically analysed using either gas chromatography (GC) with a nitrogen/phosphorus detector (NPD), or a mass spectrometer (MS). The TWA airborne nicotine concentration is calculated by dividing the amount of nicotine collected on each filter $(\mu \mathrm{g})$ by sampled volume of air $\left(\mathrm{m}^{3}\right)$.

Nicotine can be measured for a shorter period using active sampling with an adsorbent tube or treated filters. Active sampling for nicotine is typically conducted over a span of hours rather than days or weeks. Laboratory analysis methods are similar as those for passive nicotine sampling.

Active and passive nicotine sampling have been used to estimate SHSe in a variety of microenvironments including homes, hospitals, schools, offices, personal and public transportation, and hospitality venues. ${ }^{74} 76$ 79-86 As passive monitoring often requires integrating longer sampling intervals, including times without occupancy, TWA nicotine concentrations for passive sampling are usually lower than those obtained by active sampling. Both methods are highly effective, however, at discriminating between environments with and without smoking. ${ }^{37}$ The 2006 Report of the Surgeon General summarises studies in indoor venues in the USA. ${ }^{8}$ In recent years, numerous studies conducted outside the USA have assessed SHSe levels and evaluated the impacts of policies and controls to reduce exposure. 18 74 87-95

Nicotine is a tracer compound for SHSe that may not always track the mixture of toxic components found in SHS. The relationship between nicotine and other compounds in SHS may vary over time and space (specifically as nicotine is removed from the air through adsorption to surfaces).

\section{Particulate matter}

PM, a widely used measure of indoor SHSe, has been assessed in homes, offices, cars and hospitality venues. ${ }^{22} 43919396-99$ table 3 summarises the key advantages and disadvantages of measuring airborne nicotine and PM for estimating SHSe. PM in indoor air can come from many sources including outdoor air. Although there are several potential sources of PM in indoor environments (eg, cooking with solid fuels, burning candles, outdoor air pollution from open windows or ventilation), tobacco smoking 
Table 2 Summary of approaches for measuring environmental markers of secondhand smoke by chemical analyte and sampling method

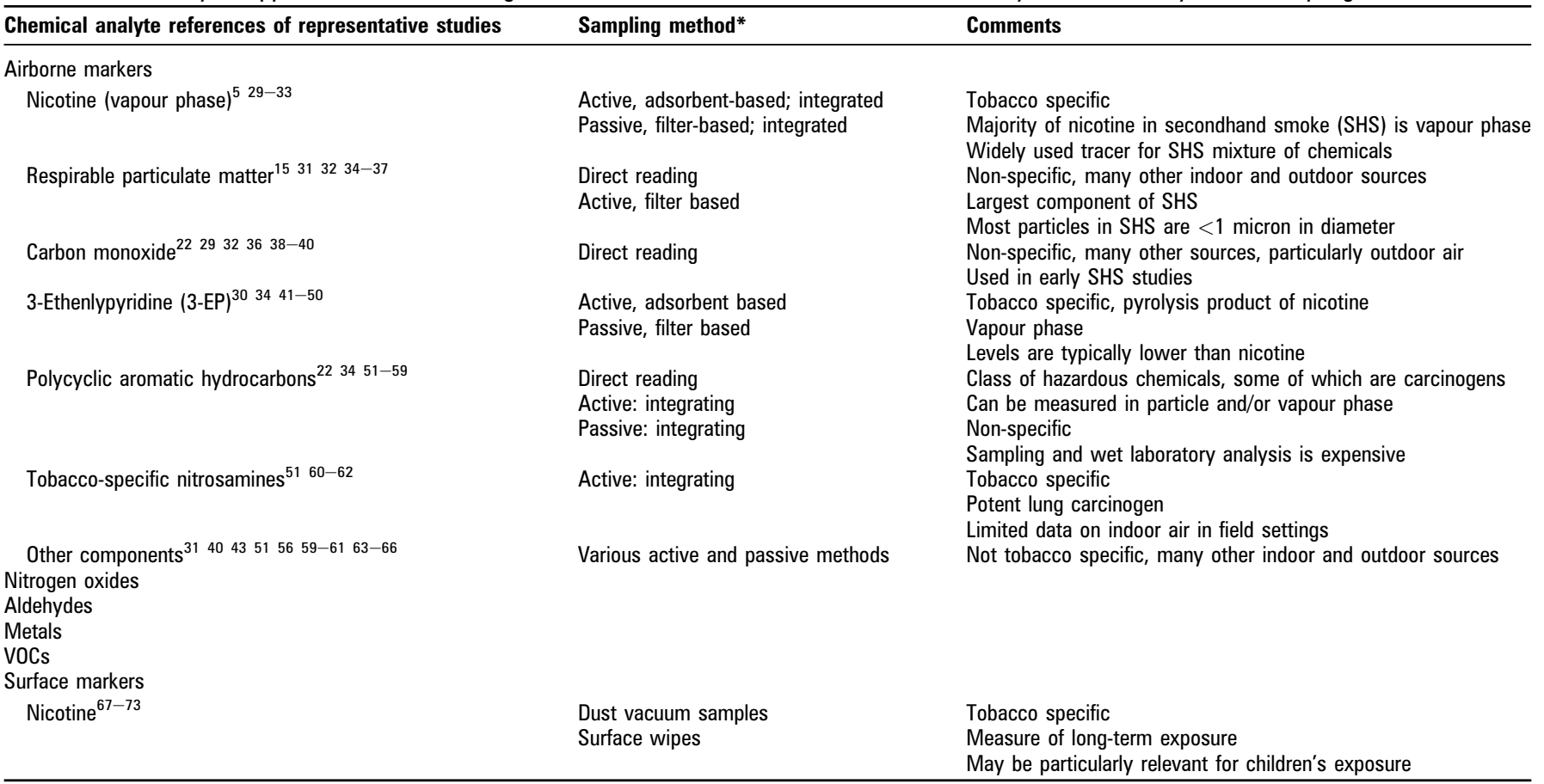

*'Direct reading' refers to the sampling and measurement of an analyte in real time. 'Integrating' refers to the collection of a sample over some defined period of time, for which a time-weighted average concentration can be estimated. Active sampling refers to the use of a pump to draw air through a collection device. Passive sampling relies on diffusion.

is often the most significant source in venues where smoking is allowed. $^{101}$ In some settings, however, high background concentrations of PM from other sources makes difficult to assess the impact of SHSe directly. ${ }^{35} 102$
PM is typically classified by aerodynamic diameter, for example, $\mathrm{PM}_{10}$ is comprised of particles less than $10 \mu \mathrm{m}$ in aerodynamic diameter. Most particles produced through tobacco smoking are smaller than $1 \mu \mathrm{m}$ in diameter. ${ }^{103}$ For this reason,

Table 3 Comparison of air nicotine and particulate matter monitoring

\begin{tabular}{ll}
\hline Airborne nicotine (passive or active sampling) \\
\hline Timescale & Duration of sampling depends on the amount of nicotine in the air and \\
sampling method (active vs passive). Active sampling generally requires \\
several hours where as passive sampling may need $1-2$ days to \\
$1-2$ weeks. For instance in a bar or nightclub where smoking is allowed \\
1 day of sampling is generally sufficient to provide a precise quantification \\
of nicotine in that environment. For any location, a week of sampling has the \\
advantage to provide a good estimate of time-weighted average \\
concentrations. \\
A sufficient amount of nicotine must be collected on the filter in order to \\
perform quantification in the laboratory. Current laboratory methods are very \\
sensitive allowing for the quantification of $\geq 0.0026 \mu \mathrm{g} / \mathrm{ml}$ of nicotine. For \\
instance, $1 \mathrm{~h}$ of sampling is sufficient to detect an average concentration of \\
\\
$\begin{array}{l}\text { Sensitivity } \\
\text { the hour of sampling. Nicotine is highly sorbing relative to other SHS }\end{array}$ \\
compounds.
\end{tabular}

Specificity Highly specific to tobacco smoke. Tobacco is generally the only source of nicotine.

Correlation Both are correlated with other SHS constituents. Especially in places where between markers there is consistent smoking there is a good correlation between nicotine and $\mathrm{PM}_{2.5}$ with an increase of about $10 \mu \mathrm{g}$ of $\mathrm{PM}_{2.5}$ for each $1 \mu \mathrm{g}$ of nicotine.

Communication Because there is no safe level of SHSe the concentration of nicotine in the environment should be zero (ie, undetectable). Any level of exposure increases health risk, although the risk is substantially higher with increasing concentrations. Nicotine itself can be of health interest as it may have some cardiovascular effects. Comparisons of air nicotine concentrations in different locations, including smoke-free environments are powerful tools in support of smoke-free initiatives. Difficult to predict health risk associated with levels of nicotine concentrations in the environment.

Cost No expensive equipment to buy up front and minimal operating cost. Per sample laboratory costs including the filter badge are approximately US $\$ 40-\$ 100$.

Particulate matter (PM) (direct reading or active filter sampling)

Measurements are taken continuously and stored in memory as often as once per second for $6-14 \mathrm{~h}$ depending on batteries used. Longer sampling would require plugging in and securing the device. Allows for the examination of changes in secondhand smoke exposure (SHSe) over time. Allows for the measurement of peak concentrations that are not seen with integrated methods. Active filter sampling provides the total mass and can be used to identify specific chemical constituents measured over the sample duration.

Highly sensitive to tobacco smoke; the machine detects levels as low as $1 \mu \mathrm{g} / \mathrm{m}^{3}$ of PM while cigarettes emit large quantities of PM, about $14000 \mu \mathrm{g}$ per cigarette

PM is not specific to tobacco smoke and there are many other sources of PM present at all times. Especially at low concentrations it may be difficult to distinguish tobacco smoke PM from other sources. Aerosol-specific calibration required.

$\mathrm{PM}_{25}$ has known direct health effects in terms of morbidity and mortality. There are existing health standards for $\mathrm{PM}_{2.5}$ in outdoor air (USEPA and WHO) that can be used to communicate the relative harm of $\mathrm{PM}_{2.5}$ levels in places with smoking. The continuous nature of sampling allows for the creation of real-time plots showing levels minute-by-minute, which can be powerful communication tools.

High initial investment (approximately US $\$ 3000$ ) but minimal operating cost. No per sample costs, that is no laboratory costs or consumables. Potential costs in labour for data reduction and analysis

\footnotetext{
Modified from Avila-Tang, 2010. ${ }^{100}$

PM, particulate matter; USEPA, United States Environmental Protection Agency.
} 
$\mathrm{PM}_{2.5}$, also known as fine PM, is frequently used as an indirect measure of SHS. Fine PM refers to PM with more potential to cause injury than larger PM because it can penetrate to the gas exchange region of the lung. ${ }^{104}$ Many studies have shown that ambient fine PM is a risk factor for increased respiratory and cardiovascular morbidity and mortality. ${ }^{104}$ As a result, the US Environmental Protection Agency regulates outdoor PM and the WHO has proposed PM guidelines for outdoor and indoor air quality. ${ }^{105-107}$ Although these standards may provide useful comparisons for measured indoor air concentrations, it is important to note that they are based on average daily or annual levels of ambient PM and are not specifically applicable to PM from SHS, although there are similarities. ${ }^{108}$

PM in indoor environments can be measured through direct reading or active sampling using a filter to collect the particles. Direct-reading devices use a pump to draw air through a light-scattering sensor measuring the real-time concentration of PM in $\mathrm{mg} / \mathrm{m}^{3}$, which is recorded continuously are widely used. $^{15} 389197109$ Direct reading PM monitors, which measure exposure in real time, may be based on other methods of analysis such as a piezobalance technique. ${ }^{15223237110}$ Regardless of the detection principle, direct reading PM instruments must be calibrated against gravimetric methods to be used to assess SHSe directly. This is a significant limitation as gravimetric calibration factors can be very different for different aerosol sources and mixtures. If used to evaluate the relative (not absolute) contribution of smoking-related PM to different environments, calibration is less important. A calibration may be an over or under estimate and may differ based on the type of monitoring and machines used. Also, the degree of bias in light-scattering instruments increases at high relative humidity $(>60 \%)^{111}$ and, as a result, readings of these instruments must be corrected for humidity effects. ${ }^{112}$

PM can also be measured directly using active, filter-based sampling followed by gravimetric analysis. PM collected on filters can also be speciated in a laboratory to identify the concentrations of chemical constituents, such as Polycyclic aromatic hydrocarbons (PAHs) or metals. Other types of PM measurements less widely used include ultraviolet PM, fluorescing PM and solanesol PM.

\section{Carbon monoxide (CO)}

Carbon monoxide is a gaseous byproduct of incomplete combustion, ${ }^{25}$ and has historically served as a marker for SHS. $^{29} 32363940113-115$ While CO is not tobacco specific and levels may increase due to ambient air pollution and indoor sources, studies have demonstrated its usefulness in discriminating between outdoor and non-smoking and smoking environments, especially if cigars are being smoked. ${ }^{22} 38115116 \mathrm{CO}$ can easily be measured using direct reading instruments containing a CO specific electronic sensor. The use of direct reading monitors makes measuring CO relatively simple. ${ }^{15} 3132113$

\section{3-Ethenylpyridine (3-EP)}

The decomposition of nicotine through pyrolysis yields vapour phase 3-EP, and 3-EP is more stable than nicotine in indoor air. ${ }^{50} 117$ The surface absorption rate of 3-EP is also lower than that of nicotine. ${ }^{50}$ Since 1998, a number of studies have used 3-EP as a SHS marker, mostly tobacco-industry funded, ${ }^{41} 424647118$ and have shown elevated levels of 3-EP in smoking versus nonsmoking areas and high correlations with nicotine and other markers. ${ }^{30} 4147$ Concentrations of 3-EP in the air are typically lower than those of nicotine, resulting from a greater number of non-detectable samples. ${ }^{8} 118$ Sampling methods for detecting
3-EP include active and passive sampling approaches. Laboratory analysis uses GC-MS or NPD.

\section{Polycyclic aromatic hydrocarbons (PAHs)}

PAHs are produced during the incomplete combustion of organic materials. ${ }^{25} 119$ There are over 100 different PAHs, and typical human exposure occurs to mixtures of these compounds. In addition to cigarette smoke, airborne sources of PAHs include automobile exhaust, coal combustion, wood burning and wildfires; dietary sources of $\mathrm{PAH}$ include grilling or charring meat. Because PAHs are not specific to tobacco, they are not routinely used as SHS markers. Some studies have shown increased concentrations of PAHs in association with greater SHSe, ${ }^{51}{ }^{56}$ while others have demonstrated no association. ${ }^{57}$ This may be due in part to the contribution of other sources of PAHs. ${ }^{51} 5657$ Recent studies, however, have shown that cigarettes emit of the order of $14 \mathrm{ng} /$ cigarette, and they report strong correlations between PM and PAH in smoking environments. ${ }^{12} 120$

Although there are more than 100 PAHs, only 10-16 are routinely measured, primarily because of the analytical techniques available. ${ }^{121}$ Further, PAHs can be found in the particle phase and the vapour phase. As a result, comparisons across studies can be highly dependent on the sampling method specific analytes measured, their physical phase and the level of background exposure. Depending on the phase of PAHs (particle or vapour), these compounds can be measured through direct reading ${ }^{22}$ or active integrated sampling, and also with realtime monitors. ${ }^{120122123}$ Laboratory analysis is conducted using GC-MS.

\section{Tobacco-specific nitrosamines (TSNAs)}

TSNAs such as NNK are potent carcinogens found in tobacco smoke. TSNAs metabolites, such as NNAL (4-(methylnitrosamino)-1-(3-pyridyl)-1-butanol) have been used as SHSe biomarkers and indicators of risk of cancer and respiratory disease. $^{124} 125$ Limited data exist to date on concentrations of NNK or other TSNAs in indoor air following tobacco smoking. ${ }^{61} 62$ The studies that have been published were conducted in controlled environments, rather than in field settings. ${ }^{51} 62$ Given the specificity to tobacco and the health risk implications of TSNAs, further research is needed to characterise the feasibility and utility of measuring this class of compounds in indoor air as SHSe markers.

\section{Other constituents}

Many other constituents of tobacco smoke have been evaluated as SHSe markers. ${ }^{31} 40425163$ These include nitrogen oxides, aldehydes, metals and volatile organic compounds; all are nonspecific to tobacco smoke but are present in it. Because of their non-specificity to SHS, these analytes are often measured in conjunction with others.

\section{Dust/surface sampling}

Dust or surface nicotine concentration can be a surrogate for long-term SHSe and may reflect the potential for indirect exposure. Dust and surface samples have been collected using a handheld vacuum cleaner containing a filter and cotton wipes treated with ascorbic acid. ${ }^{67-70} 7273109126127$ Carpets tend to accumulate more contaminants than hard surfaces and are more likely to represent long-term reservoirs of tobacco smoke constituents. Nicotine has been measured in dust samples using GC-MS ${ }^{67}$ with findings reported as concentration in $\mathrm{ng} / \mathrm{mg}$ dust or in units of $\mu \mathrm{g} / \mathrm{m}^{2}$ (dust loading). Wipe samples are analysed with HPLC-tandem mass spectrometry. Nicotine concentrations 
are typically reported as the mass of nicotine per wipe or per square metre of surface area.

Correlations between house dust nicotine levels and urinary cotinine concentrations and between self-reported smoking in the home have been reported. ${ }^{67} 7071$ In particular, long-term smoking behaviour was predictive of dust nicotine concentrations, suggesting that dust nicotine concentration reflects longterm, cumulative smoking habits, rather than just current smoking behaviour. Studies have suggested that it may be easier to eliminate tobacco-related compounds from air, and that surfaces and dust are long-term reservoirs of tobacco smoke contamination. ${ }^{67} 70-73126128129$ Contaminated microenvironments have been described as a source of third-hand smoke (THS) exposure. ${ }^{130}$ This concept appears useful because it discriminates differences in toxic agents due to ageing of chemicals from cigarettes and because it offers distinct sources of exposure through physical contact. More research is needed on the dynamics of THS exposure.

\section{CORRELATIONS BETWEEN AIRBORNE NICOTINE, PARTICULATE MATTER AND SMOKING INTENSITY}

Nicotine and PM have been among the most widely used environmental SHSe markers. These components have most often been measured separately, so that their relationship to each other has received little attention. In this section, the relationship between airborne nicotine concentrations, PM concentrations, and reported smoking intensity in indoor environments is addressed. Knowledge of relationships among these quantities is useful for retrospective exposure assessment, litigation, or to predict likely exposures and risks.

\section{Nicotine and particulate matter (PM)}

Several studies have characterised the relationship between nicotine and PM concentrations in indoor environments (table 4). In all, 17 published articles were identified using PubMed in late 2008 that reported 20 correlations. Correlations between air nicotine and PM concentrations ranged from 0.41 to 0.98. ${ }^{5} 32343546798291 \quad 131-139$ One tobacco industry-funded study conducted in several countries throughout Asia, Europe and North America reported widely disparate findings and was excluded from the summary described here. ${ }^{41}$

These correlations were used to generate a regression slope of the relationship between nicotine and PM concentrations, weighted by the number of samples in the study. The slopes for respirable suspended particles (RSP) and $\mathrm{PM}_{2.5}$ were analysed separately and found to be similar. This is not surprising since in environments where SHS is the dominant source of PM, RSP and $\mathrm{PM}_{2.5}$ samples will provide similar exposure estimates. A weighted slope of $10.3 \mu \mathrm{g} / \mathrm{m}^{3} \mathrm{PM}$ per $\mu \mathrm{g} / \mathrm{m}^{3}$ of airborne nicotine was estimated, which is in agreement with the slope reported in the 2006 SGR $^{8}$ which concludes, 'for each microgram of atmospheric nicotine in the various environments where people spend time, there is an estimated increase of about $10 \mu \mathrm{g}$ in secondhand smoke particle concentrations' 8

Although the findings from most studies were generally consistent, variability between nicotine and PM has been reported and could be due to several factors. First, PM can be generated from other non-smoking sources in the indoor environment. Second, several size cut-offs have been used to measure $\mathrm{PM}$ in relation to SHS. For example, Rumchev et al ${ }^{138}$ measured $\mathrm{PM}_{10}$, Bolte et al ${ }^{34}$ measured $\mathrm{PM}_{2.5}$, and Ellingsen et al ${ }^{132}$ reported measuring airborne dust collected on filters with a pore size $=1.0 \mu \mathrm{m}$. In addition, the collection sampling times between and among studies varied dramatically, from several hours to more than 2 weeks. For example, Bolte et al ${ }^{34}$ sampled air nicotine and PM actively for $4 \mathrm{~h}$, Rumchev et al ${ }^{138}$ collected PM actively and nicotine passively for $24 \mathrm{~h}$, and Agbenyikey et al ${ }^{91}$ collected PM actively for $30 \mathrm{~min}$ and nicotine passively for 7 days. It is expected that correlations between samples collected over different timeframes would be lower than for samples collected for the same period.

Variability in the relationship between nicotine and PM may also depend on the smoking history of the environment and the characteristics of the indoor space, including wall and floor composition. ${ }^{140}$ Although nicotine can be measured in the particle phase, it is found mostly in the vapour phase in SHS. Vapour phase nicotine has different removal processes than particles (eg, adsorption to surfaces and re-emission into the environment). ${ }^{131} 140$ Despite variation across studies, a moderate to strong correlation was most often found between concentrations of these two SHS tracers.

\section{Nicotine and smoking intensity in field settings}

Few studies describe the slope of the relationship between nicotine concentration and cigarettes smoked. Leaderer and Hammond ${ }^{35}$ report that for each cigarette smoked, week-long air nicotine concentrations measured in the main living area of residences increased by $0.026 \mu \mathrm{g} / \mathrm{m}^{3}$, on average. Among 12 studies identified using PubMed in late 2008, the correlations ranged from 0.25 to 0.88 . One limitation to comparing the associations is the differing characterisations of smoking intensity. For example, Berman et al $1^{141}$ used 'cigarettes per day smoked in the home', while O'Connor et al ${ }^{142}$ used 'total number of smokers to whom the subject was exposed'. ${ }^{143}$ Varying SHSe indices have been used, including hours of SHSe, number of smokers and proximity. The majority of measures for cigarettes smoked are questionnaire based, while some studies employed more detailed information including daily records of

Table 4 Studies reporting the particulate matter to airborne nicotine relationship (ratio) in indoor environments

\begin{tabular}{|c|c|c|c|c|}
\hline Location & Sampling method and time frame & $\mathbf{N}$ & Slope & Reference \\
\hline 16 US cities, personal exposure & PM (RSP) and nicotine: active; collected together & 1498 & 10.9 & 131 \\
\hline New York State, USA, homes & PM (RSP): activeNicotine: passive, colocated: 1 week & 47 & $9.8^{*}$ & 35 \\
\hline USA, railroads & PM (RSP): activeNicotine: active, collected together, 2 days & 306 & 8.6 & 84 \\
\hline Norway, hospitality venues & PM (airborne dust) and nicotine: active, stationary, sampled in parallel & 48 & 7.1 & 132 \\
\hline Metro Boston, USA & $\mathrm{PM}_{2.5}$ : activeNicotine: passive, collected together, 2 days, only during public access & 57 & $9.1 \dagger$ & 82 \\
\hline USA, truck cabs & $\mathrm{PM}_{2.5}$ and nicotine: active; sampling times comparable & 16 & $5.2 \ddagger$ & 133 \\
\hline Weighted slope & & 1972 & 10.3 & \\
\hline
\end{tabular}

All PM and air nicotine measurements were reported in units of $\mu \mathrm{m} / \mathrm{m}^{3}$. Studies that used log transformed data or differing time frames for PM and nicotine were excluded.

${ }^{*}$ Reported slope represents only residences with reported cigarette consumption. All residence $(\mathrm{N}=96)$ slope $=10.8$.

†Reported slope excludes two largest points. Authors also present slope representing all data points, slope $=14.8$.

$\ddagger$ Nicotine collected using stand alone filter. Authors also collected nicotine inline after PM collection, slope using inline $=5.5$.

PM, particulate matter; RSP, respirable suspended particles. 
Table 5 Hierarchy of secondhand smoke exposure assessment using environmental markers for epidemiological studies

\begin{tabular}{|c|c|}
\hline Feasibility & Approach \\
\hline \multirow{7}{*}{$\begin{array}{l}\text { Most feasible } \\
\text { Less ideal }\end{array}$} & $\begin{array}{l}\text { Modeled concentrations of relevant environments combined with survey data on typical } \\
\text { time-activity-location. }\end{array}$ \\
\hline & Modeled concentrations in relevant environments combined with individual \\
\hline & questionnaires; \\
\hline & $\begin{array}{l}\text { Personal sampling of other individuals to establish typical exposures, combined with } \\
\text { individual data on how the experience of subjects may vary from those of the people } \\
\text { sampled; }\end{array}$ \\
\hline & $\begin{array}{l}\text { Area sampling in the microenvironments of each individual at a later time period and } \\
\text { adjusted for temporal changes (e.g., prevalence of smoking) combined with } \\
\text { questionnaire data for the relevant time period; }\end{array}$ \\
\hline & $\begin{array}{l}\text { Area sampling in the microenvironments of each individual during the relevant time } \\
\text { period combined with time activity diary data for that time period; }\end{array}$ \\
\hline & $\begin{array}{l}\text { Personal sampling to establish typical exposures, which are then combined with } \\
\text { knowledge of historical changes and time activity to estimate current or historical } \\
\text { exposures during the relevant time period; }\end{array}$ \\
\hline $\begin{array}{l}\text { Least feasible } \\
\text { Ideal }\end{array}$ & $\begin{array}{l}\text { Personal sampling during the entire time period relevant to the health effect under } \\
\text { study; }\end{array}$ \\
\hline
\end{tabular}

children's exposure kept by parents ${ }^{144}$ or observation during the sampling time. ${ }^{139}$ Overall, the expected positive association between cigarettes smoked and air nicotine concentration in real-world field settings has been established.

\section{Particulate matter and smoking intensity in field settings}

The literature generally suggests an increase of $1 \mu \mathrm{g} / \mathrm{m}^{3}$ of PM for each cigarette over an extended period of time. ${ }^{69} 145146$ Across studies reviewed, correlations in field locations ranged from 0.44 to $0.82 .^{12} 343569135147-151$ The descriptors used for cigarettes smoked in these studies are even more varied than those used in the nicotine studies. For example, Hyland et al use active smoker density (eg, average number of burning cigarettes per 100 cubic metres), ${ }^{147}$ Bolte et al use number of smokers in the location, ${ }^{34}$ Brauer et al use the average number of burning cigarettes counted, ${ }^{148}$ while Leaderer and Hammond et al use the number of self-reported cigarettes smoked during the sampling period. $^{35}$ These were also collected through self-reported questionnaires or observation. Even though PM can be produced by sources other than cigarette smoking, it is clear that there is a positive relationship in field settings between the amount of smoking taking place and PM concentrations.

Environmental SHS monitoring has numerous applications in research and policy development, including studies on the adverse health effects of SHSe, research supporting development and evaluation of smoke-free legislation, and evaluations of the impact of interventions and control measures to reduce SHSe (table 5).

\section{CONCLUSIONS}

This topic assessment summarises the most widely used methods and applications for SHS environmental monitoring, including vapour-phase nicotine and respirable PM. Air nicotine measurement has the advantage of being tobacco specific. Additionally, sample collection methods are relatively straightforward, and analytical methods are sensitivity at low concentrations. However, to date, methods to measure real-time concentrations of air nicotine are not available, and therefore laboratory analysis is necessary. Airborne PM in indoor environments can be measured through direct reading or active gravimetric sampling. Direct reading instruments generate real-time concentrations; however, although tobacco smoking remains a significant source of PM in venues where smoking is allowed, in some settings, high background concentrations may make it difficult to assess small increases or changes in SHSe directly. In general, when nicotine and PM are measured in the same setting using a common sampling period, an increase in nicotine concentration of $1 \mu \mathrm{g} / \mathrm{m}^{3}$ corresponds to an average increase of $10 \mu \mathrm{g} / \mathrm{m}^{3}$ of PM. TSNAs, which are potent human carcinogens, may prove to be particularly useful SHS markers. However, to date, limited field studies have been undertaken to validate their use. In more recent years, environmental SHS monitoring has included nicotine measurement in dust and on surfaces in homes and other indoor environments to assess long-term SHSe and the potential for indirect exposure. Future studies should focus on validating dust measures as surrogates for long-term SHSe and as a possible route for indirect exposure, particularly for children. Environmental SHS monitoring should continue to provide important evidence needed to develop and implement tobacco control policies around the world.

\section{Author affiliations}

${ }^{1}$ Department of Epidemiology, Institute for Global Tobacco Control, Johns Hopkins Bloomberg School of Public Health, Baltimore, USA

${ }^{2}$ Department of Health, Behaviour, and Society, Institute for Global Tobacco Control, Johns Hopkins Bloomberg School of Public Health, Baltimore, Maryland, USA

${ }^{3}$ American Academy of Pediatrics Julius B. Richmond Center of Excellence, Elk Grove Village, Illinois, USA

${ }^{4}$ Department of Indoor Environment, Lawrence Berkeley National Laboratory, California, USA

${ }^{5}$ School of Public Health, University of California, Berkeley, California, USA

${ }^{6}$ Center for Behavioural Epidemiology and Community Health, San Diego State University, San Diego, California, USA

${ }^{7}$ Department of Health Behaviour, Roswell Park Cancer Institute, Buffalo, New York, USA

${ }^{8}$ Department of Civil and Environmental Engineering, Stanford University, Stanford, California, USA

${ }^{9}$ Department of Environmental Health Sciences, Johns Hopkins Bloomberg School of Public Health, Baltimore, Maryland, USA

${ }^{10}$ Secondhand Smoke Consultants, Repace Associates, Inc, Bowie, Maryland, USA

${ }^{11}$ Department of Preventive Medicine, University of Southern California, Los Angeles, California, USA

Acknowledgements The authors would like to thank Nicole Ammerman and Charlotte Gerczak for their technical and editing assistance, respectively. The authors would also like to thank Drs Wael Al-Delaimy, David L Ashley, Neal L Benowitz, John T Bernert, Dana Best, K Michael Cummings, Geoffrey Fong, Stephen Hecht, Sungroul Kim, Jonathan Klein, Robert McMillen and Jonathan P Winickoff for their participation in the expert meeting. 
Contributors BJA, LG, SKH, MFH, AH, NEK, JR and PNB participated in the expert meeting, drafted and revised the paper. PNB is guarantor. LMH, CCM and AN-A drafted and revised the paper. JMS and EA-T organised and participated in the expert meeting and revised the draft paper.

Funding This work was supported by grants from the Flight Attendant Medical Research Institute to the Johns Hopkins Center of Excellence; the University of California, San Francisco Bland Lane Center of Excellence; and the American Academy of Pediatrics Julius B Richmond Center of Excellence. The funding organisation had no role in the preparation of the manuscripts.

Competing interests None.

Provenance and peer review Not commissioned; externally peer reviewed.

Open Access This is an Open Access article distributed in accordance with the Creative Commons Attribution Non Commercial (CC BY-NC 3.0) license, which permits others to distribute, remix, adapt, build upon this work non-commercially, and license their derivative works on different terms, provided the original work is properly cited and the use is non-commercial. See: http://creativecommons.org/ licenses/by-nc/3.0/

\section{REFERENCES}

1. Lofroth G. Environmental tobacco smoke: overview of chemical composition and Genotoxic components. Mutat Res 1989;222:73-80.

2. National Research Council. Environmental Tobacco Smoke: Measuring Exposures and Assessing Health Effects. 3rd edn. Washington, D.C.: Nationa Academy Press; 1986

3. Repace JL, Lowrey AH. Indoor air pollution, tobacco smoke and public health Science 1980;208:464-74.

4. Spengler JD, Ferris BG Jr. Harvard air pollution health study in Six Cities in the U.S.A. Tokai J Exp Clin Med 1985;10:263-86.

5. Hammond SK, Leaderer BP. A diffusion monitor to measure exposure to passive smoking. Environ Sci Technol 1987:21:494-7.

6. Schlotzhauer SW, Chortyk OT. Effects of varied smoking machine parameters on deliveries of total particulate matter and selected smoke constituents from an ultra low-tar cigarette. J Anal Toxicol 1983:7:92-5

7. Rickert WS, Robinson JC, Collishaw N. Yields of tar, nicotine, and carbon monoxide in the sidestream smoke from 15 brands of Canadian cigarettes. Am J Public Health 1984;74:228-31.

8. United States Department of Health and Human Services. The Health Consequences Of Involuntary Exposure To Tobacco Smoke: A Report Of The Surgeon General. Washington D.C: U.S Govt Printing Off, 2006.

9. Gorini G, Gasparrini A, Fondelli MC, et al. Secondhand Smoke (SHS) Markers: Review of Methods For Monitoring Exposure Levels. Belgium: Eur Netw Smoking Prev, 2005

10. Jaakkola MS, Jaakkola JJ. Assessment of exposure to environmental tobacco smoke. Eur Respir J 1997:10:2384-97.

11. Ott WR. Mathematical models for predicting indoor air quality from smoking activity. Environ Health Perspect 1999;107(Suppl 2):375-81.

12. Repace J. Respirable particles and carcinogens in the air of delaware hospitality venues before and after a smoking ban. J Occup Environ Med 2004;46:887-905.

13. Repace JL, Lowrey AH. An Enforceable indoor air quality standard for environmental tobacco smoke in the workplace. Risk Anal 1993;13:463-75.

14. Klepeis NE, Ott WR, Switzer P. Real-time measurement of outdoor tobacco smoke particles. J Air Waste Manag Assoc 2007;57:522-34.

15. Ott WR, Klepeis NE, Switzer P. Air change rates of motor vehicles and in-vehicle pollutant concentrations from secondhand smoke. J Expo Sci Environ Epidemiol 2008;18:312-25.

16. Klepeis NE, Nazaroff WW. Modeling residential exposure to secondhand tobacco smoke. Atmos Environ 2006;40:4393-407

17. Ott WR, Klepeis NE, Switzer P. Analytical solutions to compartmental indoor air quality models with application to environmental tobacco smoke concentrations measured in a house. J Air Waste Manag Assoc 2003;53:918-36.

18. McBride SJ, Ferro AR, Ott WR, et al. Investigations of the proximity effect for pollutants in the indoor environment. $J$ Expo Anal Environ Epidemiol 1999;9:602-21.

19. Ferro AR. Effect of interior door position on room-to-room differences in residential pollutant concentrations after short term releases. Atmos Environ 2009;43:706.

20. Miller SL, Branoff S, Nazaroff WW. Exposure to toxic air contaminants in environmental tobacco smoke: an assessment for California based on personal monitoring data. J Expo Anal Environ Epidemiol 1998;8:287-311.

21. Klepeis NR, Ott WR, Switzer P. A multiple-smoker model for predicting indoor air quality in public lounges. Environ Sci Technol 1996;30:2813-20.

22. Klepeis NE, Ott WR, Repace JL. The effect of cigar smoking on indoor levels of carbon monoxide and particles. J Expo Anal Environ Epidemiol 1999:9:622-35.

23. Repace JL. Exposure to secondhand smoke. In: Ott WR, Steinenmann AC, Wallace LA, eds. Exposure Analysis. Boca Raton: CRC Press, 2007:201-36.

24. Ott WR. Mathematical modeling of indoor air quality. In: Ott WR, Steinenmann AC, Wallace LA, eds. Exposure Analysis. Boca Raton: CRC Press, 2006:411-44.

25. Ott WR, Steinenmann AC, Wallace LA. Exposure Analysis. Boca Raton: CRC Press, 2006.
26. Repace J, Al-Delaimy WK, Bernert JT. Correlating atmospheric and biological markers in studies of secondhand tobacco smoke exposure and dose in children and adults. J Occup Environ Med 2006:48:181-94.

27. Repace J. Controlling tobacco smoke pollution. ASHRAE IAQ 2005;6:11-15.

28. Repace JL, Lowrey AH. A quantative estimate of nonsmokers' lung cancer risk from passive smoking. Environ Int 1985;11:3-22.

29. Hedge A, Erickson WA, Rubin G. The effects of alternative smoking policies on indoor air quality in 27 office buildings. Ann Occup Hyg 1994;38:265-78.

30. Hyvarinen MJ, Rothberg M, Kahkonen E, et al. Nicotine and 3-ethenylpyridine concentrations as markers for environmental tobacco smoke in restaurants. Indoor Air 2000;10:121-5.

31. Sterling TD, Mueller B. Concentrations of nicotine, RSP, CO and CO2 in nonsmoking areas of offices ventilated by air recirculated from smoking designated areas. Am Ind Hyg Assoc J 1988:49:423-6.

32. Weber A, Fischer T. Passive smoking at work. Int Arch Occup Environ Health 1980;47:209-21.

33. Muramatsu M, Umemura S, Okada T, et al. Estimation of personal exposure to tobacco smoke with a newly developed nicotine personal monitor. Environ Res 1984;35:218-27.

34. Bolte G, Heitmann D, Kiranoglu M, et al. Exposure to environmental tobacco smoke in German restaurants, pubs and discotheques. J Expo Sci Environ Epidemiol 2008;18:262-71.

35. Leaderer BP, Hammond SK. Evaluation of vapour-phase nicotine and respirable suspended particle mass as markers for environmental tobacco smoke. Environ Sci Technol 1991:25:770-7.

36. Muramatsu T, Weber A, Muramatsu S, et al. An experimental study on irritation and annoyance due to passive smoking. Int Arch Occup Environ Health 1983:51:305-17.

37. Ott WR, Switzer P, Robinson J. Particle concentrations inside a tavern before and after prohibition of smoking: evaluating the performance of an indoor air quality model. J Air Waste Manag Assoc 1996:46:1120-34.

38. Waring MS, Siegel JA. An evaluation of the indoor air quality in bars before and after a smoking Ban in Austin, Texas. J Expo Sci Environ Epidemiol 2007:17:260-8.

39. Wang JN, Zhang Y. CO and particle pollution of indoor air in Beijing and its elemental analysis. Biomed Environ Sci 1990;3:132-8.

40. Olander L, Johansson J, Johansson R. Tobacco smoke removal with room air cleaners. Scand J Work Environ Health 1988;14:390-7.

41. Bohanon HR Jr, Piade JJ, Schorp MK, et al. An international survey of indoor air quality, ventilation, and smoking activity in restaurants: a pilot study. J Expo Anal Environ Epidemiol 2003;13:378-92.

42. Jenkins RA, Maskarinec MP, Counts RW, et al. Environmental tobacco smoke in an unrestricted smoking workplace: area and personal exposure monitoring. J Expo Anal Environ Epidemiol 2001;11:369-80.

43. Jenkins RA, Palausky MA, Counts RW, et al. Determination of personal exposure of non-smokers to environmental tobacco smoke in the United States. Lung cancer 1996;14 (Suppl 1):S195-213.

44. Johnsson T, Tuomi $\mathrm{T}$, Riuttala $\mathrm{H}$, et al. Environmental tobacco smoke in Finnish restaurants and bars before and after smoking restrictions were introduced. Ann Occup Hyg 2006;50:331-41.

45. Kuusimaki L, Peltonen K, Vainiotalo S. Assessment of environmental tobacco smoke exposure of Finnish restaurant workers, using 3-ethenylpyridine as marker Indoor Air 2007;17:394-403

46. Maskarinec MP, Jenkins RA, Counts RW, et al. Determination of exposure to environmental tobacco smoke in restaurant and Tavern Workers in one US City. J Expo Anal Environ Epidemiol 2000:10:36-49.

47. Phillips K, Bentley MC, Howard DA, et al. Assessment of environmental tobacco smoke and respirable suspended particle exposures for nonsmokers in prague using personal monitoring. Int Arch Occup Environ Health 1998:71:379-90.

48. Phillips K, Howard DA, Bentley MC, et al. Measured exposures by personal monitoring for respirable suspended particles and environmental tobacco smoke of housewives and office workers resident in Bremen, Germany. Int Arch Occup Environ Health 1998; 71:201-12

49. Phillips K, Bentley MC. Seasonal assessment of environmental tobacco smoke and respirable suspended particle exposures for nonsmokers in Bremen using personal monitoring. Environ Int 2001;27:69-85.

50. Vainiotalo S, Vaaranrinta R, Tornaeus J, et al. Passive monitoring method for 3-Ethenylpyridine: a marker for environmental tobacco smoke. Environ Sci Technol 2001;35:1818-22.

51. Triebig G, Zober MA. Indoor air pollution by smoke constituents-a survey. Prev Med 1984;13:570-81.

52. Lung SC, Wu MJ, Lin CC. Customers' exposure to PM2.5 and polycyclic aromatic hydrocarbons in smoking/nonsmoking sections of 24-h coffee shops in Taiwan. $J$ Expo Anal Environ Epidemiol 2004;14:529-35.

53. Siwinska E, Mielzynska D, Bubak A, et al. The effect of coal Stoves and environmental tobacco smoke on the level of urinary 1-hydroxypyrene. Mutat Res 1999;445:147-53

54. Besaratinia A, Maas LM, Brouwer EM, et al. A molecular dosimetry approach to assess human exposure to environmental tobacco smoke in pubs. Carcinogenesis 2002;23:1171-6.

55. Chuang JC, Callahan PJ, Lyu CW, et al. Polycyclic aromatic hydrocarbon exposures of children in low-income families. J Expo Anal Environ Epidemiol 1999;9:85-98.

56. Fromme $\mathbf{H}$, Dietrich $\mathrm{S}$, Heitmann $\mathrm{D}$, et al. Indoor air contamination during a waterpipe (narghile) smoking session. Food Chem Toxicol 2009;47:1636-41.

(1) 
57. Saborit JM, Aquilina NJ, Meddings C, et al. Measurement of personal exposure to volatile organic compounds and particle associated PAH in three UK regions. Environ Sci Technol 2009;43:4582-8.

58. Choi H, Perera F, Pac A, et al. Estimating individual-level exposure to airborne polycyclic aromatic hydrocarbons throughout the gestational period based on personal, indoor, and outdoor monitoring. Environ Health Perspect 2008;116:1509-18

59. Daher N, Saleh R, Jaroudi E, et al. Comparison of carcinogen, carbon monoxide, and ultrafine particle emissions from Narghile waterpipe and cigarette smoking: sidestream smoke measurements and assessment of second-hand smoke emission factors. Atmos Environ 2010;44:8-14.

60. Brunnemann KD, Cox JE, Hoffmann D. Analysis of tobacco-specific N-Nitrosamines in indoor air. Carcinogenesis 1992;13:2415-18.

61. Scherer G, von MC, von ML, et al. Biomonitoring after controlled exposure to environmental tobacco smoke (ETS). Exp Pathol 1989;37:158-63.

62. Schick SF, Glantz S. Concentrations of the carcinogen 4-(Methylnitrosamino)-1-(3Pyridyl)-1-Butanone in sidestream cigarette smoke increase after release into indoor air: results from unpublished tobacco industry research. Cancer Epidemiol Biomark Prev 2007;16:1547-53.

63. Thompson BT, Mizaikoff B. Real-time fourier transform-infrared analysis of carbon monoxide and nitric oxide in sidestream cigarette smoke. Appl Spectrosc 2006:60:272-8.

64. Vainiotalo S, Vaananen V, Vaaranrinta R. Measurement of 16 volatile organic compounds in restaurant air contaminated with environmental tobacco smoke. Environ Res 2008:108:280-8.

65. Weber A. Annoyance and irritation by passive smoking. Prev Med 1984;13:618-25.

66. Hugod C. Indoor air pollution with smoke constituents-an experimental investigation. Prev Med 1984;13:582-8.

67. Kim S, Aung T, Berkeley E, et al. Measurement of nicotine in household dust. Environ Res 2008:108:289-93.

68. Diette GB, Hansel NN, Buckley TJ, et al. Home indoor pollutant exposures among inner-city children with and without asthma. Environ Health Perspect 2007; 115:1665-9.

69. Breysse PN, Buckley TJ, Williams D, et al. Indoor exposures to air pollutants and allergens in the homes of asthmatic children in inner-city Baltimore. Environ Res 2005; $98: 167-76$

70. Willers S, Hein HO, Jansson L. Assessment of environmental tobacco smoke exposure: urinary cotinine concentrations in children are strongly associated with the house dust concentrations of nicotine at home. Indoor Air 2004; 14:83-6.

71. Whitehead T, Metayer $\mathrm{C}$, Ward $\mathrm{MH}$, et al. Is house-dust nicotine a good surrogate for household smoking? Am J Epidemiol 2009;169:1113-23.

72. Matt GE, Quintana PJ, Hovell MF, et al. Households contaminated by environmental tobacco smoke: sources of infant exposures. Tob Control 2004; 13:29-37.

73. Matt GE, Quintana PJ, Hovell MF, et al. Residual tobacco smoke pollution in used cars for Sale: air, dust, and surfaces. Nicotine Tob Res 2008;10:1467-75.

74. Navas-Acien A, Peruga A, Breysse P, et al. Secondhand tobacco smoke in public places in Latin America, 2002-2003. JAMA 2004:291:2741-5.

75. Marbury MC, Hammond SK, Haley NJ. Measuring exposure to environmental tobacco smoke in studies of acute health effects. Am J Epidemiol 1993:137:1089-97.

76. Hammond SK. Exposure of U.S. workers to environmental tobacco smoke. Environ Health Perspect 1999:107(Suppl 2):329-40.

77. Jenkins RA, Guerin MR, Tomkins BA. The Chemistry Of Environmental Tobacco Smoke: Composition An Measurement. 2nd edn. Boca Raton, Florida: Lewis Publishers, 2000.

78. Hammond SK. Evaluating exposure to environmental tobacco smoke. In: Winegar ED, Keith LH, eds. Sampling and Analysis of Airborne Pollutants. Boca Raton, Fl: Lewis Publishers, 1993:319-38.

79. Coultas DB, Samet JM, McCarthy JF, et al. Variability of measures of exposure to environmental tobacco smoke in the home. Am Rev Respir Dis 1990:142:602-6.

80. Guerin MR, Jenkins RA, Tomkins BA. The Chemistry Of Environmental Tobacco Smoke: Composition And Measurement. Chelsea, Ml: Lewis Publishers, 1992:1-330.

81. Jones MR, Navas-Acien A, Yuan J, et al. Secondhand tobacco smoke concentrations in motor vehicles: a pilot study. Tob Control 2009;18:399-404.

82. Miesner EA, Rudnick SN, Hu FC, et al. Particulate and nicotine sampling in public facilities and offices. JAPCA 1989;39:1577-82.

83. Schenker MB, Vedal S, Baatterman S, et al. Health effects of air pollution due to coal combustion in the chestnut ridge region of Pennsylvania: cross-section survey of children. Arch Environ Health 1986;41:104-8.

84. Schenker MB, Samuels SJ, Kado NY, et al. Markers of Exposure to Diesel Exhaust in Railroad Workers. Capitol City Press. Montpelier, VT: Health Effects Institute, 1990. Report №.: 33

85. Schenker MB, Kado NY, Hammond SK, et al. Urinary mutagenic activity in workers exposed to diesel exhaust. Environ Res 1992;57:133-48.

86. Wipfli H, Avila-Tang E, Navas-Acien A, et al. Secondhand smoke exposure among women and children: evidence from 31 countries. Am J Public Health 2008;98:672-9.
87. Blanco-Marquizo A, Goja B, Peruga A, et al. Reduction of secondhand tobacco smoke in public places following National smoke-free legislation in Uruguay. Tob Control 2010:19:231-4.

88. Mulcahy M, Evans DS, Hammond SK, et al. Secondhand smoke exposure and risk following the Irish smoking ban: an assessment of salivary cotinine concentrations in hotel workers and air nicotine levels in bars. Tob Control 2005:14:384-8.

89. Edwards R, Thomson G, Wilson N, et al. After the smoke has cleared: evaluation of the impact of a new national smoke-free law in new Zealand. Tob Control 2008:17:e2.

90. Fong GT, Cummings KM, Borland $\mathrm{R}$, et al. The conceptual framework of the international tobacco control (ITC) policy evaluation project. Tob Control 2006;15 (Suppl 3):iii3-11.

91. Agbenyikey W, Wellington E, Gyapong J, et al. Secondhand tobacco smoke exposure in selected public places (PM2.5 and air nicotine) and non-smoking employees (hair nicotine) in Ghana. Tob Control 2010:18:399-404.

92. Erazo M, Iglesias V, Droppelmann A, et al. Secondhand tobacco smoke in bars and restaurants in Santiago, Chile: evaluation of partial smoking ban legislation in public places. Tob Control 2010;19:469-74.

93. Gorini G. Impact of the Italian smoking ban and comparison with the evaluation of the Scottish ban. Epidemiol Prev 2011:35(3-4 Suppl. 1):4-18.

94. Kaur J, Vinayak P. Air nicotine monitoring for second hand smoke exposure in public places in India. Indian J Community Med 2011;36:98-103.

95. Nebot M, Lopez MJ, Ariza C, et al. Impact of the Spanish smoking law on exposure to secondhand smoke in offices and hospitality venues: before-and-after study. Environ Health Perspect 2009:117:344-7.

96. Connolly GN, Carpenter CM, Travers MJ, et al. How smoke-free laws improve air quality: a global study of Irish pubs. Nicotine Tob Res 2009;11:600-5.

97. Rees VW, Connolly GN. Measuring air quality to protect children from secondhand smoke in cars. Am J Prev Med 2006;31:363-8.

98. Sendzik T, Fong GT, Travers MJ, et al. An experimental investigation of tobacco smoke pollution in cars. Nicotine Tob Res 2009:11:627-34.

99. Nardini S, Cagnin R, Invernizzi G, et al. Indoor particulate matter measurement as a tool in the process of the implementation of smoke-free hospitals. Monaldi Arch Chest Dis 2004;61:183-92.

100. Avila-Tang E, Travers MJ, Navas-Acien A. Promoting smoke-free environments in Latin America: a comparison of methods to assess secondhand smoke exposure. Salud Publica Mex 2010;52(Suppl 2):S138-48.

101. Daly BJ, Schmid K, Riediker M. Contribution of fine particulate matter sources to indoor exposure in bars, restaurants, and cafes. Indoor Air 2010;20:204-12

102. Repace JL, Hyde JN, Brugge D. Air pollution in Boston bars before and after a smoking ban. BMC Public Health 2006:6:266.

103. Klepeis NE, Apte MG, Gundel LA, et al. Determining size-specific emission factors for environmental tobacco smoke particles. Aerosol Sci Technol 2003:37:780-90.

104. Institute of Medicine (IOM). Secondhand Smoke Exposure and Cardiovascular Effects: Making Sense of the Evidence. Committe on Secondhand Smoke Exposure and Acture Coronary Events. Washington DC: National Academy of Sciences, 2010

105. World Health Organization. WHO Air Quality Guidelines For Particulate Matter, Ozone, Nitrogen Dioxide, and Sulfur Dioxide. Global Update, 2005. Geneva, Switzerland: WHO Press, 2005.

106. U.S.Environmental Protection Agency. Particulate Matter Standards. 2010. http://www.epa.gov/ttn/naaqs/standards/pm/s pm index.html

107. World Health Organization. WHO Guidelines for Indoor Air Quality: Selected Pollutants. Bonn, Germany: in puncto druck+medien GmbH. 2010

108. Pope CA III, Burnett RT, Krewski D, et al. Cardiovascular mortality and exposure to airborne fine particulate matter and cigarette smoke: shape of the exposureresponse relationship. Circulation 2009;120:941-8.

109. Lee K, Hahn EJ, Pieper N, et al. Differential impacts of smoke-free laws on indoor air quality. J Environ Health 2008:70:24-30, 54.

110. Sem GJ, Tsurubayashi K. A new mass sensor for respirable dust measurement. Am Ind Hyg Assoc J 1975;36:791-800.

111. Ramachandran G, Adgate JL, Pratt GC, et al. Characterizing indoor and outdoor 15 minute average PM[Sub2.5] concentrations in urban neighborhoods. Aerosol Sci Technol 2003;37:33

112. Malm WC, Day DE, Kreidenweis SM. Light scattering characteristics of aerosols as a function of relative humidity: part I-a comparison of measured scattering and aerosol concentrations using the theoretical models. J Air Waste Manag Assoc 2000;50:686-700.

113. Akbar-Khanzadeh F, Greco TM. Health and social concerns of restaurant/bar workers exposed to environmental tobacco smoke. Med Lav 1996:87:122-32.

114. Aviado DM. Carbon monoxide as an index of environmental tobacco smoke exposure. Eur J Respir Dis 1984;133:47-60.

115. Jo WK, Oh JW, Dong Jl. Evaluation of exposure to carbon monoxide associated with passive smoking. Environ Res 2004;94:309-18.

116. Repace JL, Ott WR, Klepeis NE. Indoor air pollution from cigar smoke. In: Nationa Cancer Institute. Smoking and Tobacco Control Monograph No. 9. Cigars- Health Effects and Trends. Bethesda, MD: National Institutes of Health, National Cancer Institute, 1998

117. Bardana EJ, ed. Indoor Air Pollution and Health. New York: Marcel Dekker, Inc, 1996 
118. LaKind JS, Jenkins RA, Naiman D0, et al. Use of environmental tobacco smoke constituents as markers for exposure. Risk Anal 1999;19:359-73.

119. Agency for Toxic Substances and Disease Registry. Agency for Toxic Substances and Disease Registry (ATSDR), Public Health Statement for Polycyclic Aromatic Hydrocarbons (PAHS). Atlanta, GA: U.S Department of Health and Human Services, Public Health Service, 1995

120. Repace JL, Jiang RT, Acevedo-Bolton V, et al. Fine particle air pollution and secondhand smoke exposures and risks inside 66 US Casinos. Environ Res 2011:111:473-84.

121. U.S.Environmental Protection Agency. Methods for Organic Chemical Analysis of Municipal and Industrial Wastewater: Method 610- Polynuclear Aronmatic Hydorcarbons. 2010. http://water.epa.gov/scitech/methods/cwa/organics/upload/ 2007_07_10_methods_method_organics_610.pdf

122. Ott $\overline{\mathbf{W}} \mathbf{R}$, Siegmann $\mathrm{HC}$. Using multiple continous fine particle monitors to characterize tobacco, incense, candle, cooking, wood burning, and vehicular sources in indoor, outdoor, and in-transit settings. Atmos Environ 2006;40:821-43.

123. Repace JL. Secondhand smoke in Pennsylvania Casinos: a study of nonsmokers' exposure, dose, and risk. Am J Public Health 2009;99:1478-85.

124. Eisner MD, Jacob P III, Benowitz NL, et al. Longer term exposure to secondhand smoke and health outcomes in COPD: impact of Urine 4-(Methylnitrosamino)-1(3-Pyridyl)-1-Butanol. Nicotine Tob Res 2009;11:945-53.

125. Hecht SS. Human urinary carcinogen metabolites: biomarkers for investigating tobacco and cancer. Carcinogenesis 2002;23:907-22

126. Matt GE, Quintana PJ, Zakarian JM, et al. When smokers move out and nonsmokers move in: residential thirdhand smoke pollution and exposure. Tob Control 2011;20:e1

127. Hein HO, Suadicani $P$, Skov $P$, et al. Indoor dust exposure: an unnoticed aspect of involuntary smoking. Arch Environ Health 1991:46:98-101.

128. Benton M, Chua MJ, Gu F, et al. Environmental nicotine contamination in latent fingermarks from smoker contacts and passive smoking. Forensic Sci Int 2010;200:28-34.

129. Sleiman M, Gundel LA, Pankow JF, et al. Formation of carcinogens indoors by surface-mediated reactions of nicotine with nitrous acid, leading to potential thirdhand smoke hazards. Proc Natl Acad Sci U S A 2010;107:6576-81.

130. Winickoff JP, Friebely J, Tanski SE, et al. Beliefs about the health effects of "Thirdhand" smoke and home smoking bans. Pediatrics 2009;123:e74-9.

131. Daisey JM. Tracers for assessing exposure to environmental tobacco smoke: what are they tracing? Environ health Perspect 1999;107(Suppl 2):319-27.

132. Ellingsen DG, Fladseth G, Daae HL, et al. Airborne exposure and biological monitoring of bar and restaurant workers before and after the introduction of a smoking ban. J Environ Monit 2006;8:362-8.

133. Chiu YH, Hart JE, Smith TJ, et al. Nicotine contamination in particulate matter sampling. Int J Environ Res Public Health 2009;6:601-7.

134. Butz AM, Breysse P, Rand C, et al. Household smoking behavior: effects on indoor air quality and health of urban children with asthma. Matern Child Health $\mathrm{J}$ 2011;15:460-8.
135. Coultas DB, Samet JM, McCarthy JF, et al. A personal monitoring study to assess workplace exposure to environmental tobacco smoke. Am J Public Health 1990;80:988-90.

136. Kado NY, McCurdy SA, Tesluk SJ, et al. Measuring personal exposure to airborne mutagens and nicotine in environmental tobacco smoke. Mutat Res 1991:261:75-82.

137. LaKind JS, Ginevan ME, Naiman DQ, et al. Distribution of exposure concentrations and doses for constituents of environmental tobacco smoke. Risk Anal 1999:19:375-90.

138. Rumchev K, Jamrozik K, Stick S, et al. How free of tobacco smoke are 'smoke-free' homes? Indoor Air 2008;18:202-8.

139. Thompson CV, Jenkins RA, Higgins CE. A thermal desorption method for the determination of nicotine in indoor environments. Environ Sci Technol 1989:23:429-35.

140. Van Loy MD, Riley WJ, Daisey JM, et al. Dynamic behavior of semivolatile organic compounds in indoor air. 2. Nicotine and phenanthrene with carpet and wallboard. Environ Sci Technol 2001;35:560-7.

141. Berman BA, Wong GC, Bastani R, et al. Household smoking behavior and ETS exposure among children with asthma in low-income, minority households. Addict Behav 2003;28:111-28.

142. O'Connor TZ, Holford TR, Leaderer BP, et al. Measurement of exposure to environmental tobacco smoke in pregnant women. Am J Epidemiol 1995:142:1315-21.

143. Coghlin J, Hammond SK, Gann PH. Development of epidemiologic tools for measuring environmental tobacco smoke exposure. Am J Epidemiol 1989;130:696-704

144. Emerson JA, Hovell MF, Meltzer SB, et al. The accuracy of environmental tobacco smoke exposure measures among asthmatic children. J Clin Epidemiol 1995; 48:1251-9.

145. Wallace LA. Indoor particles: a review. J Air Waste Manag Assoc 1996:46:98-126.

146. Ozkaynak H, Xue J, Spengler J, et al. Personal exposure to airborne particles and metals: results from the particle TEAM study in Riverside, California. J Expo Anal Environ Epidemiol 1996;6:57-78.

147. Hyland A, Travers MJ, Dresler C, et al. A 32-Country comparison of tobacco smoke derived particle levels in indoor public places. Tob Control 2008;17:159-65.

148. Brauer M, Mannetje A. Restaurant smoking restrictions and environmental tobacco smoke exposure. Am J Public Health 1998;88:1834-6.

149. Jiang R0, Cheng KI, Acevedo-Bolton V, et al. Measurement of fine particles and smoking activity in a statewide survey of 36 California Indian Casinos. J Expo Sci Environ Epidemiol 2011;21:31-41.

150. Liu R, Yang Y, Travers MJ, et al. A cross sectional study on levels of secondhand smoke in restaurants and bars in five cities in China. Tob Control 2011;20:397-402.

151. Saade G, Seidenberg AB, Rees WW, et al. Indoor secondhand tobacco smoke emission levels in six Lebanese Cities. Tob Control 2010;19:138-42. 